\title{
Proceeding
}

9th INSHS International Christmas Sport Scientific Conference, 4-6 December 2014. International Network of Sport and Health

Science. Szombathely, Hungary

\section{Training and health in gymnastics}

\author{
SILVIA COPPOLA ${ }^{1} \triangle$, RODOLFO VASTOLA ${ }^{1}$, MARIA SCATIGNA ${ }^{2}$, LEILA FABIANI ${ }^{2}$ \\ ${ }^{1}$ Department of Human, Philosophical and Education Sciences, University of Salerno, Italy \\ 2 Department of Life, Health and Environmental Sciences, University of L'Aquila, Italy
}

\begin{abstract}
Coppola, S., Vastola, R., Scatigna, M., \& Fabiani, L. (2015). Training and health in gymnastics. J. Hum. Sport Exerc., 9(Proc1), pp.S391-S398. The aim of this study was to analyze the training regimens of top level rhythmic gymnasts and their state of health. The research also focused on the information provided to the athletes about the relationship between sport and health. The sample consisted of fourteen high-level Italian gymnasts aged thirteen to eighteen. The instrument used was a structured medical history interview conducted by a doctor and a graduate student in physical education. A descriptive approach was used for the data analysis. The distribution of the variables collected in the group of athletes was studied. The results showed that, on average, throughout the year the athletes do from three to five hours of training five days a week, and travel from two to sixteen days a year for competitions. Given the age of the gymnasts in particular ten to fourteen who are under fifteen years old, it is a major undertaking. Gymnasts complained some non-specific symptoms, such as weakness and dizziness, with frequencies among more than half of the sample interviewed, especially close to competition dates. This finding suggests a reaction to stress, although the simple detection is insufficient for a correct interpretation. The data collected regarding the information provided to athletes on the risks associated with strenuous and demanding exercise shows that female athletes were not informed enough about the consequences. Self-assessment of health status is within the range of 6 to 10 (mean 7.7), despite the fact that they were not undergoing any kind of treatment at the time of the assessment and the medical history did not reveal any indication of disease or injury. In conclusion, based on the results obtained in this study it can be stated that: the young athletes need an approach to education / teaching that would enable them to deal consciously and adequately the competitive commitments, which are demanding in relation to the resources of preteens; the critical aspects regarding the non-specific signs and symptoms of health problems that emerged from the self-report and from the perception of health status scale need to be studied in further depth; the scientific debate on the problematic aspects with regards to the protection and promotion of the health of young athletes may provide those elements of knowledge, health education and support to growth, which can improve the overall management and self-awareness of the athlete without compromising the performance. Key words: RHYTHMIC GYMNASTICS, TRAINING, SPORT, HEALTH.
\end{abstract}

Corresponding author. University of Salerno, via Giovanni Paolo II, 132 - 84084 - Fisciano (SA)

E-mail: sicoppola@unisa.it

9th INSHS International Christmas Sport Scientific Conference, 4-6 December 2014. International Network of Sport and

Health Science. Szombathely, Hungary.

JOURNAL OF HUMAN SPORT \& EXERCISE ISSN 1988-5202

(c) Faculty of Education. University of Alicante

doi:10.14198/jhse.2015.10.Proc1.30 


\section{INTRODUCTION}

In rhythmic gymnastics intense training usually begins at age six; the first sports competitions begin from the age of eight (Federation Internationale de Gymnastique, 2013). This discipline has grown since it became an Olympic sport in 1984. In Italy, in recent years, the number of registered gymnasts to the National Federation of Gymnastics amounts to over two hundred thousand (Comitato Olimpico Nazionale Italiano, 2015). The increase of the gymnasts involved in intense athletic training at a young age has aroused the interest of researchers as can be observed from the literature on the argument (Georgopouloset et al., 2012; Rutkauskaité \& Skarbalius, 2012; Tournis et al., 2010; Kwitniewska et al., 2009; Cupisti et al., 2007; Georgopoulos et al., 2002).

The training of high-level gymnasts consists of six phases that include neuromuscular activation, stretching, ballet, technique training, apparatus manipulation and, finally, the execution of routines (Miletić et al., 2004). The program provides national and international competitions individual and team exercises. The program of the individual gymnasts consists of four exercises with four of the five tools: rope, hoop, ball, clubs and ribbon (Heather, 2003). The program of the team, however, is composed of two routines, one with only one type of tool, the other with two types of tool. The choreography contains a balance of jumps, leaps, pivots, balances and flexibility movements. Each movement involves a high degree of athletic skill. Physical abilities needed by a rhythmic gymnast include strength, power, flexibility, agility, dexterity, endurance and coordination (Kwitniewska et al., 2009).

Training of top level gymnasts are held on average four times a week for three hours; increasing age and level workouts become daily and last for more than four hours in order to implement the provisions of the federal programs and achieve the performance objectives required by programming agonistic. The athletes of international level also train two times a day (Bertulli et al., 2008).

The practice of rhythmic gymnastics at a competitive level can cause changes in health status, including those in relation to intensive training at a young age (Jayanthi et al., 2013; Law et al., 2011). Hence, the detection of training regimens and any health problems in order to identify possible strategies for promoting the health of young gymnasts is essential. In recent years the attention of researchers focused on some characteristic factors of this discipline: dietary, anthropometric characteristics, the triad of athletes and frequency of injuries to the expert level rhythmic gymnasts' female. The results of studies related to the anthropometric characteristics and power showing a BMl lower than controls not practicing this discipline and a diet characterized by a low fat content (Gómez-Campos et al., 2013; Filaire \& Lac, 2002; Cupisti et al., 2000). Other studies have evaluated the prevalence of delayed menarche and menstrual abnormal patterns, as well as the association of menstrual status with the physical training in elite rhythmic gymnasts (Márquez \& Molinero, 2013; Georgopoulos et al., 2013; Roupas \& Georgopoulos, 2011; Torstveit \& Sundgot-Borgen, 2004; Brasili et al., 2003; Klentrou \& Plyley, 2003). As a result, it is not uncommon for female athletes to train at very high intensities, to have same healthy problems. This study aims to analyze the training regimens of top level gymnasts and investigate any issues related to the health of young athletes. It also proposes to examine the knowledge possessed by athletes in reference to the health risks of intense physical activity and the source of such information in order to identify any training needs on the theme of competitive sport at a young age and health. 


\section{MATERIAL AND METHODS}

\section{Participants}

The sample consists of professional gymnasts in the "top level" category belonging to several Italian clubs. The sample was selected by category and by voluntary enlistment and consisted of six gymnasts of a club in central Italy, which represents one of the largest "nurseries" of national gymnasts and eight gymnasts participating in the National Championship. The majority of the sample (71.4\%) are less than or equal to 14 years, the remainder is 15 years old and over. In particular, two athletes are older and this difference, detectable by the high variability (SD 1.9 years CV - coefficient of variation of $7.6 \%$ ), can be considered significant in view of the low sample size.

More than half $(57.1 \%)$ of the respondents attended secondary school, while the remaining gymnasts attended high school (Classic, Scientific, Linguistic in all cases except one); thus presenting rather a homogeneous sample with respect to the type of school. The family status was identified on the basis of the level of education and professional status of the parents. Both among mothers, as well as between the fathers prevail university degrees and high school diplomas also prevail specific professions related to the standards of income and upper-middle level (e.g. teachers, doctors, entrepreneurs). In summary, despite the size of the sample, it can be concluded that gymnasts are often from a medium-high socio-economic and cultural background.

\section{Measures}

The study predicted the development and administration of structured medical history interview conducted by a physician and a graduate in Science and Sport. The interview was structured in several sections: the first section requested information relating to demographic data; the second referred to the sports-related commitments in different periods of the year and the competition commitments off site; the third section included a self-report of symptoms and signs of fatigue, a perception of health status measured with selfrated health status (SRHS) (Manzur Farazi \& Shamsunnahar, 2014; Mikolajczyk, 2008) and history on drug therapies; the fourth and final section covered information received from athletes about the health risks associated with intense physical activity and possible sources of information they had availed of.

\section{Procedures}

The interviews were conducted by the research group on two occasions:

Chieti, during training of collegiate athletes of a company in central Italy;

Fano, during the National Championship of Rhythmic Gymnastics.

\section{Analysis}

Descriptive statistics were used for the analysis of data. The distributions of the variables in the group of athletes were measured.

\section{RESULTS}

Mean age 14.5 years

SD 1.9 years

Range from 13 to 18.9 years 
Table 1. Age distribution of the gymnasts

\begin{tabular}{ccc}
\hline Age class & $\mathrm{N}$ & Freq. $(\%)$ \\
\hline$\leq 13,5$ years & 5 & 35.7 \\
$13,5-14$ years & 5 & 35.7 \\
$\geq 15$ years & 4 & 28.6 \\
\hline Total & 14 & 100.0 \\
\hline
\end{tabular}

The sample consists of professional gymnasts in the "top level" category belonging to several Italian clubs: six belonging to a company in central Italy, which represents one of the largest "nurseries" of the national (III Championships Italian A1 series) and eight participants in the National Championship.

The majority of the sample (71.4\%) of the sample are less than or equal to fourteen years, the remainder is fifteen years old and over. In particular, two athletes are older and this difference, detectable by the high variability (SD 1.9 years CV - coefficient of variation of $7.6 \%$ ), can be considered significant in view of the low sample size.

Table 2. Distribution of the sample according to the type of education

\begin{tabular}{ccc}
\hline School & N & Freq. (\%) \\
\hline M.S. lower (11-13 years) & 8 & 57.1 \\
M.S. superiors ( $\leq 14$ years) & 6 & 42.9 \\
High School (Grammar school) & 3 & \\
High School Science & 1 & \\
Language High School & 1 & \\
Institute for Tourism & 1 & \\
\hline
\end{tabular}

More than half $(57.1 \%)$ of the respondents attended secondary school, while the remaining gymnasts attended high school (Classic, Scientific, Linguistic in all cases except one); thus presenting rather a homogeneous sample with respect to the type of school.

Table 3. Distribution according to the qualification of parents

\begin{tabular}{ccc}
\hline Parents & Mother & Father \\
\hline Average age (mean \pm SD) & $46,0 \pm 3,4$ & $47,8 \pm 3,8$ \\
\hline Qualification & $\mathrm{N}(\%)$ & $\mathrm{N}(\%)$ \\
\hline Degree / University Diploma & $5(35.7)$ & $4(28.6)$ \\
High Schools & $9(64.3)$ & $7(50.0)$ \\
Secondary Schools & -- & -- \\
NR & -- & -- \\
\hline Total & $14(100.0)$ & $14(100.0)$ \\
\hline Professional status & $\mathrm{N} .(\%)$ & $\mathrm{N} .(\%)$ \\
\hline Occupied & $12(85.7)$ & $14(100.0)$ \\
Housewife & $2(14.3)$ & -- \\
\hline Total & $14(100.0)$ & $14(100.0)$ \\
\hline
\end{tabular}


The family context has been detected on the basis of the level of education and professional status of the parents. Both among mothers, as well as between the fathers prevail university degrees and high school diplomas also prevail specific professions related to the standards of income and upper-middle level (e.g. teachers, doctors, entrepreneurs). In summary, for the sample of gymnasts outlining a socio-economic and cultural extraction medium-high particularly homogeneous despite the low number.

Table 4. Distribution according to the place of residence of the sample

\begin{tabular}{ccc}
\hline Permanent Address & $N$ & $(\%)$ \\
\hline In town & 10 & 71.4 \\
In village & 4 & 28.6 \\
\hline Total & 14 & 100.0 \\
\hline
\end{tabular}

The majority of the sample $71.4 \%$ resided in the city whereas $28.6 \%$ resided in villages.

Table 5. Time commitment related to the activities of training and the competitive commitments / sports off site by the sample of gymnasts.

\begin{tabular}{cccccc}
\hline Average number of hours of training a week & N & Average & SD & Min & Max \\
\hline Beginning of season & 13 & 19.0 & 4.7 & 10 & 25 \\
The pre-race & 13 & 23.6 & 7.8 & 10 & 35 \\
Post-race & 13 & 14.7 & 7.9 & 0 & 23 \\
Number of days of traveling for sports / competitions annually & 13 & 5.9 & 4.4 & 2 & 16 \\
\hline
\end{tabular}

Periodization of the sporting reported to several months of the year that corresponds to: normal workout, intense activity (pre-race), rest.

The athletes reported that, on average, they did nineteen hours of training a week at the beginning of season with a maximum of twenty five hours; during the period of pre-race the gymnasts, on average, did twenty three hours of training a week with a maximum of thirty-five hours.

They did three to five hours of training for five days a week and they travel from two to sixteen days a year for athletic activities.

Table 6. Self-reports of signs and symptoms of fatigue and / or overtraining

\begin{tabular}{ccc} 
Signs and symptoms & During the normal training & During the period of intense activity \\
\hline Dizziness & $35,7 \%(5)$ & $50,0 \%(7)$ \\
Muscle cramps & $35,7 \%(5)$ & $35,7 \%(5)$ \\
Weakness & $64,3 \%(9)$ & $71,4 \%(10)$ \\
Nausea & $14,3 \%(2)$ & $7,1 \%(1)$ \\
Nervousness & Not required & $35,7 \%(5)$ \\
Drop in performance & Not required & $35,7 \%(5)$
\end{tabular}

The table shows the reporting rate of self-referential signs / symptoms of clinical fatigue due to overtraining or referred to two regimes of physical activity, normal training and intense sports activity. The events most 
frequently reported are the "physical weakness" (the complaint 64.3\% [9] of the gymnasts during the normal training and $71.4 \%$ [10] in the period of most intense activity) and "dizziness" (admitted by $35.7 \%$ [5] of the gymnasts in the period of normal activity and $50 \%$ [7] in the period of most intense activity).

Drug therapies in the past and present

Nearly half of the respondents $(42.9 \%)$ reported the use of anti-inflammatory medication in the past and antipyretic hypothetically related to the usual nosological employ of girls in this age group (febrile episodes, menstrual pain) and perhaps partly inflammatory musculoskeletal apparatus skeletal arising from sport. However, there were no data on the frequency / dose of intake so any assumptions about the therapeutic motivations or possible misuse or excessive use, is quite unlikely.

Table 7. Information on risks to health (N. 12 interviews)

Information on the risks ... in an intense sport

Athletes who have received information

$16,7 \%(2)$

Athletes who have not received information

$83,3 \%(10)$

The table shows the frequency of athletes who claim to have received information on issues concerning relations between sport and health. Only two say they were informed about the risks of an intense sports activity $(16.7 \%)$.

Scale perception of health status

The self-rated health status (SRHS) was evaluated using a rating scale. The gymnasts assess their state of health with an average of $7.7 \pm 1.0$ (range 6-10).

\section{DISCUSSION}

The results show a remarkable homogeneity of the sample with respect to socio-economic status.

The difference in the ages of the athletes makes it difficult to consider a homogeneous group.

The athletes reported that, on average throughout the year, they did three to five hours of training for five days a week and they travel from 2 to 16 days a year for athletic activities. Given the age of the gymnasts, especially 10 to 14 who are less than 15 years of age, is a major undertaking.

Gymnasts complain some nonspecific symptoms, such as weakness and dizziness, with frequencies greater than half of the sample, especially at periods of intense activity. This figure suggests, rather, a reaction to stress, although the simple detection is insufficient for a correct interpretation.

A reading can be shown in table 1.7 on the information received, in particular with regard to the risks associated with a sport intense and demanding, which shows that the athletes are just as prepared to face.

A similar uncertainty demonstrates the self-assessment of health status in the range of 6 to 10 (mean 7.7). Neither the recognition of therapies, either by history emerges any indication of disease states. 


\section{CONCLUSIONS}

In relation to the relatively low number and the relative homogeneity of the sample and the impossibility of repeated detections makes this a pilot study. The results are, therefore, rather suggestive than conclusive, and open up the field to the need for further investigation.

In particular, many aspects of the analysis of training regimens and any signs and symptoms of overtraining of young athletes could be clarified by examining a broader sample of athletes belonging to different categories and in different stages of their athletic growth.

Based on the results obtained in this study, in conclusion, we can say that:

- The young athletes need an educational approach/teaching that would enable it to deal consciously and serenely the competitive commitments, which are heavy in relation to the resources of pre-adolescents:

- The critical aspects emerged from self-report on the signs and symptoms of overtraining and scale perception of health status deserve a deepening and a specific reflection;

- The scientific debate on the problematic aspects of the protection and promotion of the health of young athletes, would make the elements of knowledge, health education and support to the growth, which can improve the overall management and self-awareness of the athlete without compromising performance.

\section{REFERENCES}

1. Bertulli, G., \& Piazza, M. (2008). La ginnastica rítmica. Medicina dello sport, 61(4), pp. 504-513.

2. Brasili, P., Toselli, S., \& Lolli, F. (2003). Menarcheal age in girls active in artistic and rhythmic gymnastics. Italian Journal of Sport Science 19, pp.27-40.

3. Comitato Olimpico Nazionale Italiano. (2015). I numeri dello sport - a cura del Centro Studi CONI. Roma.

4. Cupisti, A., D’Alessandro, C., Castrogiovanni, S., Barale, A., \& Morelli, E. (2000). Nutrition survey in elite rhythmic gymnasts. J Sports Med Phys Fitness, 40, pp.350-5.

5. Cupisti, A., D'Alessandro, C., Evangelisti, I., Umbri, C., Rossi, M., Galetta, F., ... Piazza, M. (2007). Injury survey in competitive sub-elite rhythmic gymnasts: results from a prospective controlled study. The Journal of Sports Medicine and Physical Fitness, 47(2), pp.203-207.

6. Fédération Internationale de Gymnastique, (2013). Code of Points.

7. Filaire, E., \& Lac, G. (2002). Nutritional status and body composition of juvenile elite female gymnasts. Journal of Sport Medicine and Physical Fitness, 42, pp.65-70.

8. Georgopoulos, N., Markou, K., Theodoropoulou, A., Paraskevopoulou, P., Varaki, L., Kazantzi, Z., ... Vagenakis, A.G. (2013). Growth and Pubertal Development in Elite Female Rhythmic Gymnasts. The Journal of Clinical Endocrinology \& Metabolism, 84(12), pp.4525-4530.

9. Georgopoulos, N.A., Markou, K.B., Theodoropoulou, A., Benardot, D., Leglise, M., \& Vagenakis, A.G. (2002). Growth Retardation in Artistic Compared with Rhythmic Elite Female Gymnasts. The Journal of Clinical Endocrinology \& Metabolism, 87(7), pp.3169-3173.

10. Georgopoulos, N.A., Theodoropoulou, A., Roupas, N.D., Rottstein, L., Tsekouras, A., Mylonas, P., ... Markou, K.B. (2012). Growth velocity and final height in elite female rhythmic and artistic gymnasts. Hormones, 11(1), pp.61-69.

11. Gómez-Campos, R., Camargo, C., Arruda, M., \& Cossio Bolaños, M.A. (2013). Crecimiento físico y estado nutricional de gimnastas rítmicas de élite. Nutrición clínica y dietética hospitalaria, 33(1), pp.31-37. 
12. Heather, C., \& Palmer. (2003). Teaching Rhythmic Gymnastics - A developmentally appropriate approach. Library of Congress Cataloging in Publication Data, pp.10-15.

13. Hobson, A.J. (2002). Epidemiological study of injuries in club-level Rhythmic Gymnastics. College of Kinesiology, pp.20-30.

14. Jayanthi, N., Pinkham, C., Dugas, L., Patrick, B., \& LaBella, C. (2013). Sports Specialization in Young Athletes Evidence-Based Recommendations. Sports Health: A Multidisciplinary Approach, 5(3), pp.251-257.

15. Klentrou, P., \& Plyley, M. (2003). Onset of puberty, menstrual frequency, and body fat in elite rhythmic gymnasts compared with normal controls. Br J Sports Med, 37, pp.490-494.

16. Kwitniewska, A., Dornowski, M., \& Hökelmann, A., (2009). Quantitative and Qualitative Analysis of International Standing in Group Competition in the Sport of Rhythmic Gymnastics Product Information Baltic. Journal of Health and Physical Activity, 1(2), pp.118-125.

17. Law, M.P., Côté, J., \& Ericsson, K.A. (2011). Characteristics of expert development in rhythmic gymnastics: A retrospective study. International Journal of Sport and Exercise Psychology, 5(1), pp.82-103.

18. Manzur Rahman, F., \& Shamsunnahar, T. (2014). Mediators of University Students 'Self-Rated Health Status: A Study in Jahangirnagar University Daffodil International University. Journal of Science and Technology, 9(1), pp.19-27.

19. Márquez, S., \& Molinero, O. (2013). Energy availability, menstrual dysfunction and bone health in sports. Nutr Hosp., 28(4), pp.1010-1017.

20. Mikolajczyk, R.T., Brzoska, P., Maier, C., Ottova, V., Meier, S., Dudziak, U., ... Ansari, W.E. (2008). Factors associated with self-rated health status in university students: a cross-sectional study in three European countries. BMC Public Health, 8(215).

21. Miletić, Đ., Katić, R., \& Maleš, B. (2004). Some Anthropologic Factors of Performance in Rhythmic Gymnastics. Novices Coll. Antropol. 28(2), pp.727-737.

22. Nordina, S., Harrisb, G. \& Cumming, J. (2003). Disturbed eating in young, competitive gymnasts: Differences between three gymnastics disciplines. European Journal of Sport Science, 3(5), pp.114.

23. Roupas, N.D., \& Georgopoulos, N.A. (2011). Menstrual function in sports. Hormones, 10(2), pp.104-116.

24. Rutkauskaitè, R., \& Skarbalius, A. (2012). Models and interaction of intensive training and sport performance of 14-15-year-old athletes in rhythmic gymnastics. SPORTAS, 4(87), pp.57-64

25. Sundgot-Borgen, J. (1996). Eating disorders, energy intake, training volume, and menstrual function in high-level modern rhythmic gymnasts. International Journal of Sport Nutrition, 6(2), pp.100-109.

26. Torstveit, M.K., \& Sundgot-Borgen, J. (2005). Participation in leanness sports but not training volume is associated with menstrual dysfunction: a national survey of 1276 elite athletes and controls. Br J Sports Med, 39, pp.141-147.

27. Tournis, S., Michopoulou, E., Fatouros, I.G., Paspati, I., Michalopoulou, M., Raptou, P., ... Pappaioannou, N. (2010). Effect of rhythmic gymnastics on volumetric bone mineral density and bone geometry in premenarcheal female athletes and controls. J Clin Endocrinol Metab. 95(6), pp.2755-62. 